\title{
Aproximación a la investigación “El parlamentarismo español en la perspectiva de sus corresponsales de prensa. De Galdós al Siglo XXI"
}

\author{
Pablo Delgado Cuenca \\ Universidad Complutense de Madrid \\ pablogdc@hotmail.es
}

\section{INTRODUCCIÓN}

1 1 centenario de Benito Pérez Galdós ha aumentado el interés sobre su persona. Hace pocas fechas la Biblioteca Nacional acogía la exposición «Benito Pérez Galdós. La verdad humana», dedicada según sus comisarios, los profesores Germán Gullón y Marta Sanz, a dar a conocer las múltiples facetas del autor canario. Las centenares de publicaciones académicas que han abordado en las últimas décadas todos los rincones de su biografía dan cuenta de ello: el Galdós músico y pintor, sus descripciones toponímicas y geográficas de ciudades como Santander, Gerona o Toledo; la relación con su tierra natal; el papel de la mujer en su obra, su correspondencia y relación con personajes como Antonio Maura o Azorín, cuestiones como por qué no consiguió el Nobel frustrado en 1905, el anticlericalismo, vida personal, vida amorosa, evolución ideológica y activismo político, las adaptaciones al cine de algunas de sus novelas, y un largo etcétera. Por supuesto la faceta del Galdós periodista no puede faltar en toda biografía que se precie, sin embargo el tiempo dedicado al periodismo parlamentario ha sido tratado de pasada por la mayoría de autores que se han aproximado a Galdós en general, y a su labor periodística en particular.

Aproximarnos a una faceta tan concreta como la de periodista parlamentario en el diario Las Cortes, nos presenta un gran reto por delante: llenar el vacío historiográfico que supone la historia del periodismo parlamentario español. 


\section{MOTIVACIÓN}

El 25 de septiembre de 2014 Televisión Española estrenaba la película televisiva: "Prim, asesinato en la calle del Turco". Dirigida por Miguel Bardem y protagonizada por Francesc Orella, la cinta aborda la tarea que fue traer a Amadeo I a España en medio de la conspiración para asesinar al general Prim. Javier Godino da vida al Benito Pérez Galdós de la época, dedicado en aquella ficción al periodismo parlamentario mientras estrenaba su primera novela: La Fontana de Oro (1870). Por tanto, la única aparición en una película del personaje Galdós es precisamente en aquella etapa del periódico Las Cortes. No deja de ser llamativo que el Galdós menos conocido por las razones que más adelante expondremos, el Galdós periodista parlamentario, haya sido coprotagonista de una película. Por tanto, uno ya retiene en su cabeza que el gran literato, cumbre del realismo y autor de 'Trafalgar' que le enseñaron en el colegio, fue también periodista ${ }^{1}$.

Aquel mismo 2014 las elecciones europeas introdujeron al partido Podemos en la actualidad política y mediática española, a colación de los cinco eurodiputados que obtuvieron aquel 25 de mayo. El interés en la actualidad política por parte de la opinión pública iría en crescendo con la entrada de este y otros nuevos partidos en el Parlamento, las repetidas elecciones generales, el proceso interno de los partidos políticos, con el cambio generacional entre muchos otros factores, seguido todo minuto a minuto por la cobertura mediática y las redes sociales. Hoy los plenos y comisiones del Parlamento nacional y autonómicos se retransmiten en directo, el lenguaje de los políticos se ha adaptado, hoy es menos técnico; en más de una ocasión la Cámara del Congreso ha acogido una situación, persona o comentario que ha dado pie a polémicas mediáticas, etc. Y todo ello sin que sea necesaria la función mediadora del periodista entre la información y el público. Sin duda, la Historia política española nunca ha estado tan cerca de la población.

Este contexto también ha suscitado un enorme interés de la opinión pública por la Historia. Declaraciones de líderes políticos sobre personajes de nuestro pasado han elevado a personajes como Felipe II, Adolfo Suárez, Lluis Companuys, Largo Caballero o las trece rosas a la categoría de trending topic en más de una ocasión. Cabe destacar que la inmediatez con la que se trata a

1 Faceta abordada, entre otras, por la célebre necrólogica que le dedicó Víctor Gabirondo el 5 de enero de 1920 en La Libertad. 
la Historia en estas ocasiones trae de cabeza a los historiadores, también por hacer de estas oportunidades mediáticas armas arrojadizas y del reproche ideológico. Esta situación ha producido mucha rabia entre mis colegas estudiantes e investigadores. Una inmediatez de la que el periodismo ha sido parte importante, de ahí el cliché que muchos de nosotros tenemos hacia esta profesión. Además, opiniones y reflexiones de veteranos periodistas criticando esta actitud del 'bombardeo' mediático de sus colegas en activo, especialmente en lo que a la información parlamentaria se refiere, alimentan la idea de estudiar cómo ha cambiado esta profesión.

\section{HIPÓTESIS Y METODOLOGÍA}

La primera pregunta es: ¿dónde comenzamos este recorrido histórico del trabajo del periodista parlamentario? ¿En la etapa Galdós, en 1869?. Documentándome para ello, la lectura de 'Historia del periodismo en España', de la profesora María Cruz Seoane, y de biografías divulgativas de Azorín, quizás el periodista parlamentario más extensamente estudiado de nuestra historia, suscita otra pregunta: ¿por qué quedarnos en Galdós?, ¿por qué no construir una historia del periodismo parlamentario en España?

Ante una nueva línea de investigación, la hipótesis que por ahora manejo es: “QQué metodología debe emplear un historiador para estudiar la evolución del periodismo parlamentario en España?".

Estamos hablando de doscientos años de construcción de una faceta de la profesión del periodista, que no siempre ha sido denominada ni "profesión" ni "periodismo" ${ }^{2}$; de decenas de personas dedicadas a un trabajo cuyo objetivo es explicar a la opinión pública las decisiones y leyes que toma el Poder Legislativo, su desarrollo creativo, así como la estrategia de las fuerza políticas para lograrlo, contando además con la opinión de la línea editorial de cada medio, sea prensa, radio o televisión.

Desde las Cortes de Cádiz, todas las legislaturas están documentadas, así como los diputados que formaron parte de ellas, junto a los debates, y leyes y medidas que vieron la luz, o no. Las actas que guardan toda esta infor-

2 En el caso de Galdós y como periodista, no había una carrera universitaria u organismo que diese el título de periodista: periodista es el que vivía de los periódicos y al que pagaban por ello. (Pinacho, 2001: 42). 
mación constituyen una fuente primaria fundamental para nuestra Historia. De la misma manera, para conocer el día a día de la vida parlamentaria que dio a luz esas leyes que reglaron la vida de la población, es imprescindible acercarnos a las noticias redactadas por los periodistas que trabajaban en ellas, de gran valor historiográfico, así como la visión que de la institución parlamentaria tenían ${ }^{3}$.

Es preciso además conocer el contexto histórico de cada época, y dentro de éste, tres partes: situación política, marcada por la vida parlamentaria; marco jurídico, haciendo especial hincapié en lo que a leyes de libertad y restricción de prensa se refiere; y contexto periodístico (número de periódicos y su financiación, líneas editoriales, etc).

Las fuentes primarias que nos aproximan a la historia de los periodistas parlamentarios son fundamentalmente tres: la información redactada en los medios de comunicación, memorias escritas ${ }^{4}$ y testimonios. Ante tantísimos periodistas que han cubierto la información en las Cortes, una buena selección la encontramos en la exposición "Periodistas en las Cortes", organizada por la Asociación de la Prensa de España y la Fundación General de la Universidad de Alcalá. Fue inaugurada el 15 de junio de 2006 por los reyes en el Congreso de los Diputados, siendo sus comisarios Juan Oñate y Juan García Cerrada. Los organizadores fueron los periodistas Miguel Ángel Aguilar y Víctor Márquez, y los historiadores José Álvarez Junco, Juan Pablo Fusi, Santos Juliá, Charles Powell y María Cruz Seoane. La idea fue elegir a quince periodistas que hubiesen cubierto la información en las Cortes entre las Cortes de Cádiz y la guerra civil ${ }^{5}$. Cada uno sería retratado por un dibujante ${ }^{6}$, como Gallego y Rey, Mingote, entre otros.

Los periodistas seleccionados fueron ${ }^{7}$ José María Blanco, White (17751841), Fermín Caballero (1800-76), Mariano José de Larra (1809-37), Ramón

\footnotetext{
3 Cuenca Toribio, 1993: 3.

4 Algunos ejemplos pueden ser “Juego de escaños" (2017) de María Rey o “El Show De Sus Señorías: Antología De Anécdotas Parlamentarias" (1985) de Luis Carandell.

5 Consultado el 28 de enero de 2020. http://www.elnotario.es/index.php/hemeroteca/revista-14/ la-perspectiva/2388-periodistas-colgados-de-la-pared-0-1993564862751928

6 Consultado el 28 de enero de 2020. http://www.apeuropeos.org/galeria-de-retratos-de-periodistas-en-las-cortes/

7 Están situados por año de nacimiento. Cabría distribuirlos también por los años en que estuvieron en activo en el Congreso.
} 
Campoamor (1817-1901), Isidoro Fernández Flórez, Fernanflor (1840-1902), Benito Pérez Galdós (1843-1920), Francisco Cañamaque (1851-91), Leopoldo Alas, Clarín (1852-1901), José Martínez Ruiz, Azorín (1873-1967), Indalecio Prieto (1883-1962), Julio Camba (1884-1962), Wenceslao Fernández Flórez (1885-1964), Margarita Nelken (1894-1968), Josep Pla (1897-1981) y Josefina Carabias (1908-80).

A las pautas marcadas anteriormente para abordar a cada uno de estas quince personas: contexto histórico (político, jurídico y periodístico), escritos en prensa, memorias (si tienen) y testimonios orales (en todo caso de gente que fue testigo de su trabajo), habría que añadir las pertinentes investigaciones académicas biográficas y que concretamente aborden su producción periodística en el Parlamento, si es que las hay.

Para abordar el contexto actual, y en lo que a testimonios se refiere, antes de comenzar el confinamiento en marzo de 2020, había entrevistado a cuatro periodistas de diferentes medios y que trabajan o han trabajado en el Congreso de los Diputados ${ }^{8}$. Accedí a todos ellos por recomendaciones personales de conocidos. Aparte de ello se puede acceder a los periodistas que cubren la información parlamentaria mediante sus perfiles en redes sociales, y que se pueden encontrar en las páginas webs de los periódicos, así como en las listas de premiados por el premio "Luis Carandell" o los de la "Asociación de Periodistas Parlamentarios". Empleé por tanto la metodología de las fuentes orales, interesándome por cuestiones como sus inicios, sus referentes profesionales, el cambio que han supuesto las redes sociales, los momentos que les han demandado más trabajo, su día a día laboral, etc. No me detendré ahora en sus respuestas para ordenar la información del Galdós periodista parlamentario, pero espero poder hacerlo en futuras ocasiones escritas y oradas.

\section{¿DÓNDE ESTÁ LAS CORTES?}

El principal problema para estudiar al Galdós periodista parlamentario es que el periódico donde ejerció como tal, Las Cortes, no se halla digitalizado

8 Ante la posibilidad de seguir entrevistando por videoconferencia, prefiero esperar y hacerlo en un mismo espacio físico. 
en la Hemeroteca Digital de la Biblioteca Nacional ni en ningún archivo9. A falta de este material, a día de hoy sí puedo ofrecer la recopilación de las referencias de diferentes autores que han estudiado a Galdós, y que han hecho referencia a su labor como periodista parlamentario. En el apartado 6 abordaré la excepción que confirma la regla. Pero antes de nada, abordemos la trayectoria del joven Galdós previa a entrar en este medio.

\section{GALDÓS ENTRE 1863 Y 1869}

a. 1863-1866. Galdós entra a los 19 años, en el curso 1862-63, a la ciudad de Mesonero Romanos y Larra en transformación. Siendo el pequeño de once hermanos y con una formación intelectual y personalidad creativa y autodidacta que le había garantizado cierta fama en su ciudad natal de Las Palmas, llega a Madrid para estudiar Derecho.

Los años universitarios le marcan más por la vida extrauniversitaria. No tenía vocación por estudiar Derecho ${ }^{10}$, se forma en la cultura oral de las tertulias, cafés y el Ateneo, del que se hace socio en noviembre de $1865^{11}$ (el centro cultural más importante: va por las tardes y las noches) ${ }^{12}$. La tertulia será el puesto de observación de la sociedad, y que cambiará posteriormente por el Parlamento ${ }^{13}$. En aquellos foros con personajes que firmaban en periódicos, conoce Ricardo Molina, quien le introduce en la prensa nacional.

Autores que han trabajado la etapa del periodista Galdós han sido Shoemaker, Hoar o Brian J, Dendle. Éstos y muchos otros se pueden encontrar en el estado de la cuestión Galdós y la prensa: hacia una revisión crítica de la mina inagotable de Rhian Davies (2013). Una etapa la de periodista denominada por Fernández Montesinos, uno de los principales críticos de Galdós, como 'la prehistoria del novelista', otorgándole un tinte peyorativo. Por el contra-

\footnotetext{
9 Además de ello, Hoar advierte que el tipo de periódico, por su contenido tan exclusivo, supone un escollo para su búsqueda. (Hoar, 1974 pág 7).

10 Casalduero, 1974: 16.

11 Ortiz-Armengol, 1996: 89.

12 Valora especialmente del Ateneo su espíritu de tolerancia y respeto por las personas e ideas, que los jóvenes se mezclen con los viejos, estudiantes con profesores, conservadores con liberales, religiosos con librepensadores, etc. Para Galdós el Ateneo fue para el 68 lo que la Enciclopedia para la Revolución Francesa, así lo describe en Prim (1906). Casalduero, 1974: 17.

13 Íbid., 16.
} 
rio, se defiende el trabajo de Galdós como periodista, más como prólogo ${ }^{14}$ que prehistoria, como una experiencia precursora de su futura y consagrada obra novelesca, y que tiene a varios apologetas, como son algunos de sus principales biógrafos: Hyamn C. Berkowitz, Pedro Ortiz Armengol, María del Pilar García Pinacho o Joaquín Casalduero.

En el momento en que Galdós empieza, La Correspondencia de España (1859) lidera el sector con una tirada de 50.000 ejemplares (20.000 en Madrid) ${ }^{15}$ : su director, Manuel María de Santa Ana se convierte en un pionero del periodismo de empresa en España ${ }^{16}$. Este periódico nace con el respaldo de O'Donnell y la Unión Liberal para informar sobre las expediciones internacionales, defenderá la candidatura de Montpensier y posteriormente la restauración alfonsina. Su principal competidor es El Imparcial (1867), valedor del rey Amadeo, más tarde republicano para acabar integrado en el sistema canovista. Cabe destacar que en su suplemento literario: Los lunes de El Imparcial se estrenaron Pardo Bazán, Clarín, Unamuno, Azorín, Benavente, Pérez de Ayala, Caia, etc... son secciones fijas de arte, ciencia, industria, ocio. En un ambiente donde los periódicos eran tribunas políticas, se fundan periódicos anarquistas, marxistas, republicanos, carlistas, etc. Para profundizar en el contexto periodístico destaca el segundo tomo de Historia del periodismo en España (1987) de María Pilar Cruz Seoane y Movimientos literarios y periodismo en España (1997) de María del Pilar Palomo.

Galdós trabajará en varios periódicos antes de su entrada en Las Cortes en 1869. Caben aquí dos divisiones temporales: 1866 y 1868, marcados por la revuelta del cuartel de san Gil y la revolución gloriosa.

b. 1865-1866. En 1865 encontramos a Galdós en La Nación y Revista Intelectual de Europa. El primero es un periódico liberal y progresista, considerado progresismo moderado y el sector más joven y ágil del partido progresista $^{17}$, nacido el 2 de mayo de 1864 y fundado por Pascual Madoz ${ }^{18}$. Galdós tiene 22 años y es su primer contacto con la prensa de la capital

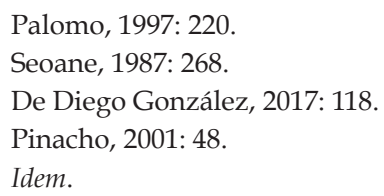


exceptuando el poema 'El pollo' en otro diario ${ }^{19}$. Los ciento treinta y un artículos que deja en este periódico le sirven para forjar una escritura sencilla y eficaz ${ }^{20}$. Los sucesivos directores quieren crónicas sobre temas de actualidad artística, intelectual y política, cuestiones en las que Galdós vive sumergido gracias a sus paseos y tertulias y regulares visitas a teatros ${ }^{21}$, óperas, conciertos, exposiciones, verbenas, etc. Siendo su principal actividad intelectual, muestra sus preocupaciones e intereses ${ }^{22}$, sin dejar de lado que todo gira en torno a Madrid ${ }^{23}$, comenzando así el proceso de 'madrileñanización" ${ }^{24}$, Galdós también trabaja en la "Revista del Movimiento Intelectual de Europa". Se trata de una revista dominical de ocho páginas pequeñas algo menores que una cuartilla por dos columnas ${ }^{25}$ filial del diario madrileño Las Novedades. Como en La Nación, escribe sobre teatros, música y sociedad matritense en dos secciones. Además, escribir en este periódico, supone que adquiere prestigio en seguida ${ }^{26}$.

La profesora García Pinacho en sus tesis La prensa como fuente y subtema de los «Episodios nacionales» de Benito Pérez Galdós (2001) valora la importancia de esta etapa en el futuro Galdós novelista: se documenta de la historia del país con las fuentes periodísticas en las vive sumergido, especialmente $\mathrm{La}$ Gaceta (el entonces Boletín Oficial del Estado), crea a sus personajes en base a la ideología que recoge la prensa, así como la voz de la opinión pública. Además, sus personajes periodistas tendrán la cualidad de conocer el poder político, e influir en la Historia ${ }^{27}$. Cabe destacar la serie titulada Galería de españoles célebres, que arranca el 7 de enero 1866 y donde retrata escritores y políticos del momento ${ }^{28}$, futuros personajes esbozados de sus novelas ${ }^{29}$. Con el bagaje adquirido por este tiempo en prensa comienza con La Fontana de Oro engrasando política, costumbrismo e historia.

\footnotetext{
Pinacho, 2001: 49.

Bonet, 2006: 65.

Bravo-Villasante, 1970: 33.

Pinacho, 2001: 49.

Programa de trabajo sobre la ciudad que ya ama. (Ortiz-Armengol, 1996: 88).

Palomo, 1997: 221.

Ortiz-Armengol, 1996: 90.

Onrubia, 2015: 2.

Pinacho, 2001: 45.

Empieza retratando a Mesonero Romanos. Admira su manera de describir Madrid, técnica que tanto le caracterizará en el futuro. (Palomo, 1997: 221).

29 Bravo-Villasante, 1970: 34.
} 
Galdós destaca porque, pese a su juventud, tiene una capacidad de análisis y conocimiento para cuestiones den profundidad sean musicales, artísticos, literarios, etc, que muy pocos tienen.

c. 1866-1868. Cabe destacar que las noticias políticas aparecen en menor medida por la censura del gobierno de Isabel II: sí encontramos críticas sutiles al régimen30.

El levantamiento del Cuartel de San Gil en junio de 1866 deja 200 muertos en Madrid. Se trata del primer golpe militar contra la reina desde la segunda guerra carlista en 1848. La censura se recrudece contra la prensa progresista en la que trabajaba Galdós, de hecho La Nación se suspende entre junio de 1867 y enero de 1868. La reacción legislativa y ejecutiva a la que se veían sometidos los profesionales de la prensa progresista, fuerza el surgimiento del corporativismo y unificación de redacciones.

Galdós marcha a Canarias en otoño de 1866, quizás para rendir cuentas a su familia por haber perdido el curso universitario o porque le pidiesen volver tras haber conocido los sucesos de junio en el archipiélago ${ }^{31}$.

Entre junio y octubre de 1868 viaja con su hermana, cuñado, concuñada y sobrina a Francia entre junio y octubre. A su vuelta la Revolución Gloriosa le sorprende en Barcelona: comienza el Sexenio Democrático. Una de las primeras medidas del gobierno del general Serrano es el decreto el 23 de octubre de $1868^{32}$, que restaura la Libertad de Prensa, una ley que implica ayudas económicas a la prensa, abaratar el precio del papel, reducir derechos del timbre y la supresión del depósito previo ${ }^{33}$, y que se consolida en el artículo 17 de la Constitución de 1869, Surgen unos 600 periódicos de toda clase y de diferente difusión, aunque en general discreta ${ }^{34}$ por su breve esperanza de vida mientras que los periódicos de gran tirada aumentan sus ventas, en pos del descenso de los científicos o literarios ${ }^{35}$.

Los acontecimientos del Sexenio van muy deprisa y la ciudadanía de-

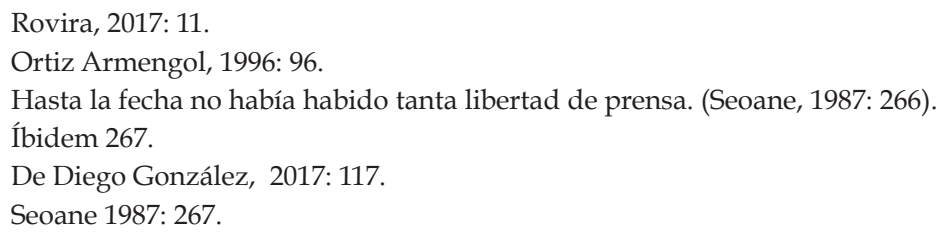


manda esa información a la prensa. Diferentes temas copan la actualidad: la guerra franco-prusiana en el orden internacional, la evolución de las juntas revolucionarias que surgieron para desarrollar la Gloriosa, y que ahora amenazaban al gobierno de Serrano; los levantamientos populares y republicanos federales, reclamaciones como la supresión de órdenes religiosas y libertad de cultos, juicios por jurados, etc, y por supuesto la búsqueda de un rey para España tras 168 años de Corona borbónica. Esta actividad explota el telégrafo y nacen agencias de noticias.

\section{GALDÓS, PERIODISTA PARLAMENTARIO}

A raíz de la proclamación de la Cortes Constituyentes de $1869^{36}$ nace el periódico vespertino Las Cortes, dirigido por Aníbal Álvarez Ossorio ${ }^{37}$. Se trata de un periódico progresista que responde al personalismo de su fundador, el general San Miguel $^{38}$. Galdós empieza a trabajar el 11 de febrero de 1869, el día que se constituyen las nuevas Cortes, y lo abandona el 31 de diciembre de 1869. Tendrá un papel secundario, de gacetillero ${ }^{39}$.

Sin la fuente primaria que suponen los números de aquel periódico, la investigación más cercana a la etapa de Galdós en su redacción data de 1973, su título es Politics and Poetry: More Proof of Gald6s' Work for Las Cortes, y su autor Leo J. Hoar, uno de los primeros estudiosos del Galdós periodista tanto dentro como fuera de España.

Hoar asegura en su investigación de veintiuna páginas que manejó 245 números de Las Cortes, y ha deducido la participación de Galdós en 106 artículos de la sección Crónica parlamentaria, entre el 23 de febrero y el 30 de noviembre de 1869. Galdós escribirá entre el 23 de febrero y 6 de junio ambos inclusive, y tras su estancia en Las Palmas vuelve el 2 de octubre ${ }^{40}$. Cabe destacar que no volverá a pisar su tierra natal hasta 1894.

\footnotetext{
36 Palomo, 1997: 221.

37 Este periodista dirigió también el periódico “Gaceta Médica Forense” entre 1863 y 1864, llegando a ser diputado y gobernador de provincias. Cofundó también la Asociación de Escritores y Artistas en 1891. (Ossorio, 1904: 14).

38 Sedeño Rodríguez, 1994: 6.

39 Gómez Aparicio, 180: 2017.

40 De ahí y hasta el final de su participación en el periódico la Crónica parlamentaria será más breve debido a la decepción de Galdós con el desarrollo de las sesiones y comportamiento de los políticos (Gómez Aparicio, 2017: 11).
} 
En Las Cortes no se le puede rastrear, al no encontrar firma alguna con su nombre o iniciales, excepto el artículo: El aniversario de la muerte de Cervantes del 23 de abril de $1869^{41}$. Por ese motivo sus artículos han pasado inadvertidos para muchos investigadores del estudio del periodismo español para poner fechas de colaboración. Pero no era el único que no firmaba en aquel diario: nadie lo hacía, y en general tampoco en el sector. Algunas de las razones de Galdós, extrapolables a otros colegas del momento pueden ser: inseguridad a pesar de su estilo inconfundible ${ }^{42}$, anonimato debido a que el periodismo era considerado más un oficio que una profesión a la que se dedicaban publicistas, más que periodistas ${ }^{43}$, y por tanto no era una labor de prestigio ${ }^{44}$; o por seguridad en un momento en que la represión a los medios de prensa era habitual ${ }^{45}$. Comparando con otros artículos que sí firmó en anteriores periódicos, se puede evidenciar que es el autor por el estilo, como en Los hombres del día, donde se refiere a Castelar, Echegaray, Marots, Becerra y Gabriel Rodríguez, con un estilo parecido a sus Galerías de hombres ilustres de La Nación ${ }^{46}$.

Su sección es Crónica parlamentaria, dedicada a dar cuenta de los debates legislativos mediante crónicas a modo de resúmenes y reseñas ${ }^{47}$. Escribirá una diaria acerca de las intensas sesiones parlamentarias.Ortiz-Armengol considera a ésta la legislatura más importante del siglo XIX después de las Cortes de Cádiz ${ }^{48}$, pues el Parlamento elabora la nueva Constitución y elige a Amadeo I como rey de España.

Caben destacar dos fuentes primarias donde aparece mencionado este periódico, aunque muy por encima eso sí: Apuntes para un catálogo de periódicos madrileños. Desde el año 1661 a 1870 (1894), de Eugenio Hartzenbusch y Ensayo

\footnotetext{
41 Además, en 1868 estando en La Nación había publicado uno parecido, y el de Las Cortes lo reeditará en 1872 y 1898 en otros El Debate y Vida Nueva, respectivamente. (Hoar, 1973: 6).

42 Ortiz Armengol, 1996: 112.

43 Onrubia, 2015: 2.

44 Palomo, 1997: 220.

45 Hoar, 1973: 8.

46 Íbidem 4.

47 La sección Crónica parlamentaria en todos los manuales consultados aparece bajo la denominación La Tribuna del Congreso, sin embargo Hoar asegura que el nombre correcto no es ese, sino aquel. todos los periódicos designaban de manera diferente su la crónica del Parlamento, y el de Las Cortes sería esa y no otro. (Hoar, 1974 pág 7).

48 Ortiz Armengol, 1996: 112.
} 
de un catálogo de periodistas españoles del siglo XIX (1904) de Manuel Ossorio y Bernard.

En el tiempo que trabajó Galdós en este periódico encontramos 186 sesiones celebradas en el Congreso ${ }^{49}$, siendo la más importante la del 1 de junio, que aprueba la Constitución de 1869. La elección de Amadeo I se produciría el 16 de noviembre de 1870, con Galdós trabajando en El Correo de España y ya fuera de Las Cortes. Por tanto, podemos aquí apuntar una licencia tomada por Miguel Bardem en la película que citábamos anteriormente, y en la que veíamos a Galdós en el puesto de los periodistas en el momento de la votación de Amadeo I y trabajando en la redacción de Las Cortes. Con algunos de ellos entabla amistad ${ }^{50}$. Este contacto y experiencia trabajando en el Parlamento le servirá para documentar a los personajes reales que hará partícipes en sus novelas ${ }^{51}$. Además, la profesora García Pinacho a colación del trabajo que desarrolla posteriormente Galdós en la Revista de España, 'su colaboración en Las Cortes puede ser la causa más directa de que sus artículos en la Revista de España contemplen la política con una perspectiva más histórica y general ${ }^{52}$. Esta experiencia germinará sus futuras habilidades y preocupaciones políticas ${ }^{53}$ : es la primera toma de contacto con la política parlamentaria tras años conociendo a diputados y grandes oradores en otros foros y analizando el contexto político en medios con los que no había accedió al Parlamento. Ahora les trata mano a mano en los pasillos del Parlamento.

Galdós se refirió vagamente a su participación en Las Cortes, sin mencionar el nombre de periódico en sus Memorias. En la biografía de Los grandes españoles: Galdós, para la que fue entrevistado por Anton de Olment y Arturo García Carraffa, sí reconoce que trabajó en aquel periódico ${ }^{54}$. Un periódico que habría dejado de funcionar el 16 de noviembre de 1870 con la proclamación de Amadeo ${ }^{55}$.

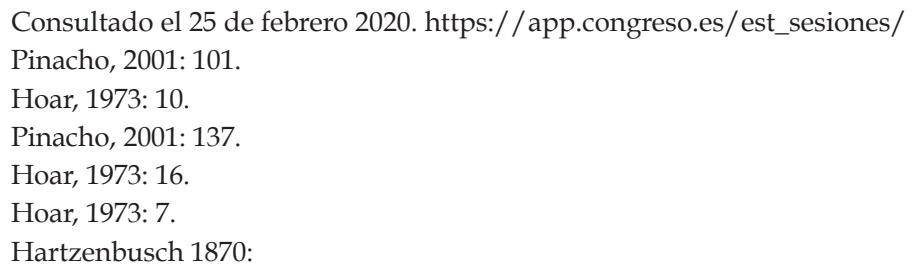




\section{EL CANTO DE CISNE. 1870-1873}

Tras su experiencia en Las Cortes trabajará en la Revista de España y en diciembre del mismo año entra como director a El Debate no contando aún los treinta años. Periódico fundado por José Luis Albareda, su línea editorial defiende al general Prim, el cual lo ha financiado ${ }^{56}$. Trabaja en él hasta octubre de 1872, componiendo 278 editoriales, algunas de ellas anónimas.

Colaborará también en El Correo de España entre 1870 y 1872, Revista de España de enero de 1872 a octubre de 1873, fundada también por Albareda en marzo 1868, siendo el contenido científico, literario y político. Galdós terminará dirigiendo este magazine entre febrero de 1872 y noviembre de $1873^{57}$. Dirige también La Ilustración de Madrid entre enero y mayo de 1872, aportando además su Crónica de la Quincena. Además, publica en La Guirnalda, Vida nueva, España nueva, La Ilustración de Madrid y La república de las letras e ideas y figuras.

Años de intenso trabajo en los que mereció la alabanza de sus coetáneos por su soltura y profundidad a la hora de abordar diferentes temas, así como críticas $^{58}$. El lenguaje y prosa del autor se desarrollan: brilla sin rival, su estilo está más trabajado y sin gran ornamentación lingüística ${ }^{59}$. Hay menciones a cuestiones del Sexenio Democrático en prácticamente todas las crónicas ${ }^{60}$ : busca corregir los defectos del nuevo régimen progresista, apoyar sus virtudes, animar a sus héroes y derribar con la pluma sus antagonistas ${ }^{61}$. Ataca a republicanos federales, socialistas, comunistas parisinos, internacionalistas, carlistas y alfonsinos por diferentes razones, con permiso de Ruiz Zorrilla, al que también dedica duras críticas.

Todo ello en una línea editorial considerada conservadora, dedicada a defender la monarquía de Amadeo I, y que no respondía solamente a los medios donde trabajaba, sino a la trayectoria que venía trabajando desde La

\footnotetext{
56 El general desdeña a la prensa, pero ante la gran cantidad de prensa hostil a Amadeo I, busca un órgano en ese punto. (Gómez Aparicio, 2017: 179).

57 Este periódico alcanzará un gran prestigio intelectual. (Sedeño, 1994: 7).

58 Onrubia, 2015: 4.

59 Rovira, 2017: 11.

60 Rovira, 2017: 27.

61 Idem.
} 
Nación ${ }^{62}$. La llegada de la República el 11 de febrero de 1873 termina con la monarquía que tanto había defendido, y este hecho colma el vaso de un pensamiento que venía madurando desde hacía tiempo.

Galdós lleva años dando muestra de que quiere dedicarse a otra cosa. En 1870 prologa Proverbios ejemplares de Ventura Ruiz Aguilera con Observaciones sobre la novela contemporánea en España ${ }^{63}$. Se trata de una fuente fundamental para el estudio galdosiano porque en sus líneas proyecta las bases de su futura obra ${ }^{64}$.Además en 1872 compone la sátira y auto-burla: El artículo de fondo, donde se confiesa desencantado con el periodismo combativo. Unos meses después publica Trafalgar, el primero de los Episodios Nacionales y su cuarta novela.

En 1875 abandona el periodismo como principal fuente económica hasta 1884, pero seguirá colaborando intermitentemente el resto de su vida ${ }^{65}$ en más de 20 periódicos. De hecho muchas de sus novelas las publicará como folletín, en periódicos antes que en libro. Nunca dejará de leer prensa, en parte porque se basa en notas y artículos de opinión: los medios quieren contar con artículos de Galdós.

\section{AÑOS DESPUÉS}

Entre el 20 de diciembre de 1883 y el 31 de marzo de $1894^{66}$ encontramos a Galdós vinculado a La Prensa de Buenos Aires realizando crónicas de la política española ${ }^{67}$. Se une al Partido Liberal de Sagasta, llegando a ocupar un acta de diputado por Puerto Rico entre 1886 y 189068. En 1907 volverá a ser elegido diputado, esta vez por Madrid hasta que en la legislatura 1914-1915 ocupe acta por Las Palmas ${ }^{69}$. En medio de este lapso de 17 años se produce el

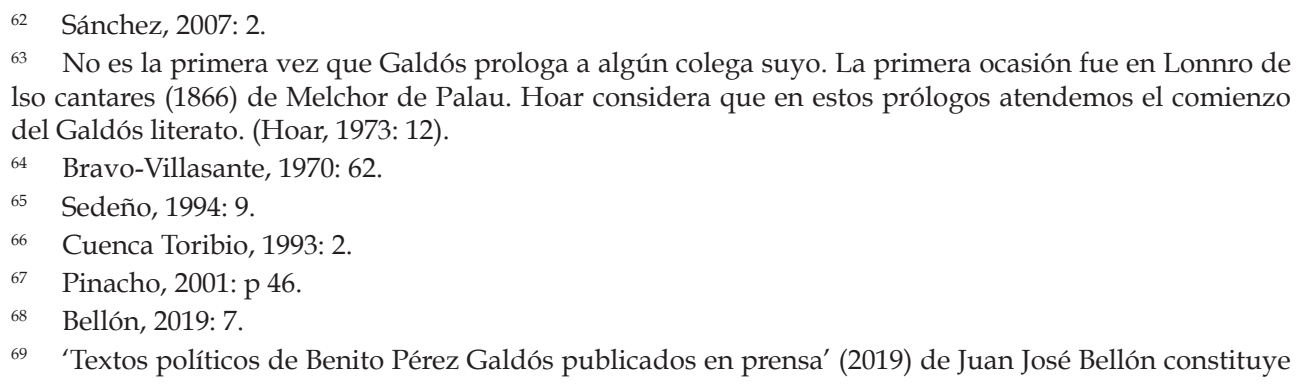

No es la primera vez que Galdós prologa a algún colega suyo. La primera ocasión fue en Lonnro de lso cantares (1866) de Melchor de Palau. Hoar considera que en estos prólogos atendemos el comienzo del Galdós literato. (Hoar, 1973: 12).

64 Bravo-Villasante, 1970: 62.

65 Sedeño, 1994: 9.

66 Cuenca Toribio, 1993: 2.

67 Pinacho, 2001: p 46.

68 Bellón, 2019: 7.

69 'Textos políticos de Benito Pérez Galdós publicados en prensa' (2019) de Juan José Bellón constituye 
Desastre del 98, acontecimiento que le motiva a realizar la tercera serie de los Episodios Nacionales (1898-1900). La vida parlamentaria aparece de nuevo, pero no la recrea con la esperanza de las series anteriores, sino con escepticis$\mathrm{mo}^{70}$. En la siguiente saga (1902-1907) había hecho referencia a la tribuna de los periodistas del Congreso ${ }^{71}$ y en 1907 Galdós comienza a escribir la quinta y última serie de los Episodios. El año 1869, en el que trabajó en Las Cortes, ocupa el desarrollo de los dos primeros números de la serie: España sin rey (1907) y España trágica (1909), protagonizada esta segunda por su álter ego: Vicente Halconero. Sin embargo en los Episodios no son nombrados ni aquel periódico ni compañeros suyos como José Calderón Llanes ${ }^{72}$, Eduardo de Inza $^{73}$ o Faustino Méndez Cabezola ${ }^{74}$. Sí aparecen en estos y otros Episodios otros medios y periodistas.

Han pasado cuatro décadas y Galdós se sirve de aquella experiencia vital y analítica para construir estos relatos de ficción donde engrasa novela, autobiografía, crónica y periodismo. Al contrario del joven Galdós, moderado y defensor del Sexenio, el Galdós que escribe España sin rey y España trágica vive decepcionado con el régimen de la Restauración al considerar que ha fracasado, y es pesimista por la actitud de la sociedad española ${ }^{75}$.

\section{CONCLUSIÓN}

A pesar de no disponer de los ejemplares de Las Cortes y de las limitaciones que supone el confinamiento para investigar, el ejercicio de profundizar en la etapa del Galdós periodista parlamentario, con sus antecedentes y contexto político, jurídico y periodístico, puede ser aplicado a otros periodistas más o

\footnotetext{
una buena aproximación al Galdós político.

70 Montesinos, 1968.

71 Bravo-Villasante, 1970: 35.

72 Entre 1865 y 1870 fue redactor en Madrid, además, de 'La Discusión', 'La Reforma' y 'La Constitución'. M. OSSORIO Y BERNARD. Ensayo de un catálogo de periodistas españoles del siglo XIX, Volumen I, p 62.

73 Ossorio y Bernard le describe como periodista y escritorio cómico, redactor de periódicos madrileños: El teatro español (1849), La verdad (1860-1863), Las Noticias (1864-66), Los Sucesos (1966-69), finalizando en las Cortes entre 1869 y 1870. Íbidem, p 207.

74 Estos y otros periodistas como Rafael María de Labra que trabajaron en Las Cortes aparecen en la compilación de Ossorio y Bernard. Al igual que Galdós canario de nacimiento, Méndez Cabezola fue investido catedrático en 1869, mientras trabajaba en Las Cortes. Íbidem, p 272.

75 En 'Galdós ante el Sexenio', Raquel Sánchez López analiza la evolución ideológica entre los dos Galdós.
} 
menos conocidos, más o menos actuales. Ésta puede ser una manera de trabajar la historia del periodismo parlamentario español: la compilación completa de los extractos biográficos de cada uno de los personajes, en lo que a su etapa como periodista parlamentario se refiere. También podríamos hacerlo por periódicos, medios de comunicación líneas editoriales e ideológicas, etapas históricas... el tiempo y la profundización en esta parte de la historia del periodismo de nuestro país orientará las diferentes estrategias para abordarlo y ofrecer un análisis completo a nuestra sociedad, en un momento en que la política española y la manera de explicar su actualidad no deja de cambiar.

\section{REFERENCIAS BIBLIOGRÁFICAS.}

Bellón Fernández, Juan José (2019). «Textos políticos de Benito Pérez Galdós publicados en prensa», en Congreso Internacional de Estudios Galdosianos 11.

BONET, Laureano (2006). «Galdós y la Nación. Años de aprendizaje literario», en Yolanda Arencibia y Ángel Bahamonde (coord.), Galdós en su tiempo, Santa Cruz de Tenerife, Parlamento de Canarias, págs. 65-68.

Bravo-Villasante, Carmen (1970). Galdós visto por sí mismo. Madrid, EMESA.

Casalduero, Joaquín (1974). Vida y obra de Galdós (1843-1920). 1974. Madrid, Gredos.

Cuenca Toribio, José Manuel (1993). «Galdós, cronista parlamentario», en Anuario de estudios Atlánticos, 39, págs 107-118.

DAVIES, Rhian (2013). «Galdós y la prensa: hacia una revisión crítica de la mina inagotable», en VIII Congreso Internacional Galdosiano.

Diego GonZÁlez, Álvaro de. (2017). De la propaganda imperial al «Parlamento de papel»: historia de la prensa en España. Madrid, UDIMA.

FERnÁndez Montesinos, José (1968). Galdós I, Madrid, Gredos.

García Pinacho, María del Pilar (2001). La prensa como fuente y subtema de los «Episodios nacionales» de Benito Pérez Galdós, Universidad Complutense de Madrid. 
Gómez Aparicio, Pedro (2017). Historia del Periodismo Español De la Revolución de Septiembre al desastre Colonial, Madrid, Editora Nacional.

Hartzendbusch e Hiriart, Eugenio. Apuntes para un catálogo de periódicos madrileños desde el año 1661 al 1870 (1894).

Martínez Onrubia, Carmen (2015). «Un joven periodista llamado Pérez Galdós: testimonios coetáneos» en X Congreso Internacional Galdosiano, Cabildo de Gran Canaria.

Ortiz Armengol, Pedro (1996). Vida de Galdós. Madrid, Critica.

Ossorio y BERNARD, Manuel (1903). Ensayo de un catálogo de periodistas españoles del siglo XIX, Volumen I, Madrid, Madrid. Imprenta y litografía de J. Palacios.

Palomo, María del Pilar (1997). Movimientos literarios y periodismo en España. Madrid, Síntesis.

Rovira Martínez de Contrasta, María Isabel (2017). Los aprendizajes de Benito Pérez Galdós: del periodista política al novelista (1865-1876), Universidad de Barcelona.

SÁNCHEz LóPez, Raquel (2007). «Galdós ante el Sexenio Democrático», en Cuadernos de Historia Contemporánea 2007. Universidad Complutense de Madrid.

Sedeño Rodríguez, Francisco J (1994). «Sobre el periodismo de Galdós. Años de aprendizaje», en Analecta malacitana: Revista de la Sección de Filología de la Facultad de Filosofía y Letras 17, págs. 71-90

SeOAne, María Cruz (1987). Historia del periodismo en España. 2, El siglo XIX. Madrid, Alianza. 


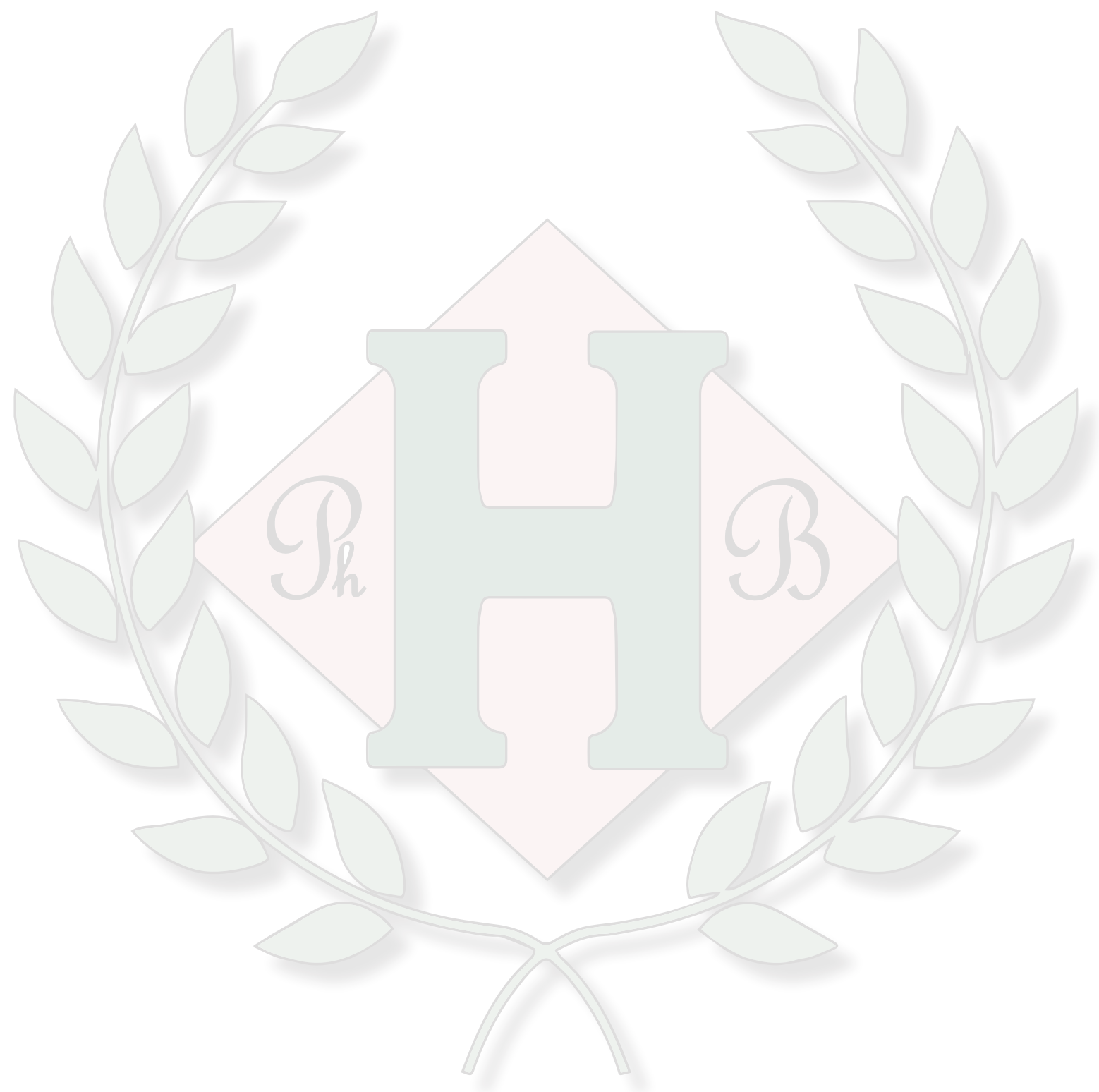

